\title{
Characterization of the Intrinsic Amorphous Silicon (a-Si:H) Layer Prepared by Remote-PECVD for Heterojunction Solar Cells: Effect of the Annealing Treatment on Multi-crystalline Si Wafer
}

\author{
Minsung Jeon,* Kazuki Kawachi, Piyasak Supajariyawichai, Marwan Dhamrin, and Koichi Kamisako \\ Department of Electronic and Information Engineering, \\ Tokyo University of Agriculture and Technology, 2-24-16 Nakacho, Koganei, Tokyo 184-8588, Japan
}

(Received 10 April 2008; Accepted 25 April 2008; Published 8 May 2008)

\begin{abstract}
The effect of hydrogenated amorphous silicon (a-Si:H) intrinsic layers, deposited on boron-doped multicrystalline silicon (mc-Si) wafers at various deposition temperatures, on heterojunction solar cells prepared using the radiofrequency remote PECVD method are investigated. The structural and optical properties of the a-Si:H films formed at various deposition temperatures that ranged from 50 to $400^{\circ} \mathrm{C}$ changed with increasing temperature. The effective carrier lifetimes of the mc-Si wafers with the a-Si:H films increased with increasing deposition temperature to a maximum of $250^{\circ} \mathrm{C}$. Furthermore, the wafers passivated with the a-Si:H films deposited temperatures below $250^{\circ} \mathrm{C}$, and the effective carrier lifetime drastically improved to about 2-5 times its as-deposited value and over the chemical passivation lifetime after annealing treatment at $350^{\circ} \mathrm{C}$. It was found that a combination of a-Si:H film deposition and annealing treatment provides excellent bulk passivation. [DOI: 10.1380/ejssnt.2008.124]
\end{abstract}

Keywords: Chemical vapor deposition; Crystalline-amorphous interfaces; Remote-PECVD; Intrinsic hydrogenated amorphous silicon (a-Si:H) layer; Heterojunctions

\section{INTRODUCTION}

Since Sanyo Electric Co. reported on the so-called HIT (heterojunction with intrinsic thin film) solar cells, the heterojunction solar cells based on hydrogenated amorphous silicon/crystalline silicon (a-Si:H/c-Si) have been found to be one of the most feasible alternatives to conventional c-Si solar cells [1]. The a-Si:H/c-Si heterostructured solar cells have attracted a lot of industry and research institutions due to its low-temperature fabrication processing with high conversion efficiency and simultaneous surface passivation [2-4]. Heterojunction solar cells typically utilize a thin, amorphous silicon emitter $\left(\mathrm{n}^{+} / \mathrm{p}^{+}\right)$ layer $(<20 \mathrm{~nm})$ with an ultra-thin a-Si:H intrinsic layer (i-layer) on crystalline silicon ( $\mathrm{p} / \mathrm{n}$ type). The main advantage of using a-Si:H i-layers are that they passivate the silicon surface in an excellent way.

Many studies focusing on the importance of the a-Si:H intrinsic layer in $\left(\mathrm{p}^{+}, \mathrm{n}^{+}\right) /(\mathrm{n}, \mathrm{p})$ heterojunction solar cells have been reported recently. For instance, Taguchi et al. [5] has reported on the high-efficiency (more than $21 \%$ ) HIT cell, and Wang et al. [6] reported on a high open-circuit voltage due to the a-Si:H intrinsic layer inserted between an a-Si:H emitter and a c-Si base to reduce the rear surface recombination velocity. This a-Si:H intrinsic layer is normally deposited using the plasmaenhanced chemical vapor deposition (PECVD) method. The PECVD method has inherent drawbacks, however, such as the damage it causes on the deposited film due to high-energy particles. On the other hand, the remote PECVD method has some advantages with respect to film deposition at low temperatures because of its high plasma density, low surface recombination velocity, and less ion bombardment on the surface $[7,8]$. The film quality of the a-Si:H film is very sensitive to deposition conditions. Fujiwara et al. [9, 10] reported the characteristics of a$\mathrm{Si}: \mathrm{H} / \mathrm{c}-\mathrm{Si}$ heterojunction solar cells as a function of the

*Corresponding author: joseph@cc.tuat.ac.jp growth temperature, using real-time spectroscopic ellipsometry (SE). They realized that the a-Si:H film quality depends on the deposition temperatures.

This study investigated the characteristics of the a-Si:H film as an intrinsic layer deposited on mc-Si wafers, using the remote-PECVD method as a function of the film deposition temperature for heterojunction solar cells, including the intrinsic layer. The structural and optical properties, and the effective carrier lifetimes of the asdeposited a-Si:H films at various temperatures, were estimated. Furthermore, after deposition of the a-Si:H film on mc-Si wafers, thermal annealing treatment was carried out and changes in the film's properties were examined.

\section{EXPERIMENTAL}

Figure 1 shows the radio-frequency remote-PECVD reactor that the authors developed. The a-Si:H films were deposited concurrently on glass substrates (Corning \#1737), Fz p-type c-Si wafers, and B-doped mc-Si wafers in the remote PECVD chamber. The hydrogen $\left(\mathrm{H}_{2}\right)$ gas, which was introduced perpendicularly against supported pure silane $\left(\mathrm{SiH}_{4}\right)$ gas as the $\mathrm{Si}$ source, was discharged by inductively coupled RF plasma $(13.56 \mathrm{MHz})$, and the generated hydrogen radicals reacted with the $\mathrm{SiH}_{4}$ molecules. The $\mathrm{H}_{2}$ and $\mathrm{SiH}_{4}$ gas flows during the deposition were kept to 150 and 5 sccm, respectively. The substrate temperatures were changed from 50 to $400^{\circ} \mathrm{C}$ for structural and optical measurement. Table I lists the detailed experimental conditions.

The a-Si:H film was deposited on glass substrates, and half of it was etched in a diluted potassium hydroxide $(\mathrm{KOH})$ solution to measure the film's thickness. The step height between the as-deposited a-Si:H film and the etched layer on the glass substrate was determined with a DEKTAK thickness profilometer. The infrared absorption was performed in the 400 to $4,000 \mathrm{~cm}^{-1}$ range with a Fourier transformed infrared spectrophotometer (FTIR) to evaluate the film contents, including the hydrogen bonds. The hydrogen contents $\left(C_{\mathrm{H}}\right)$ were calculated 


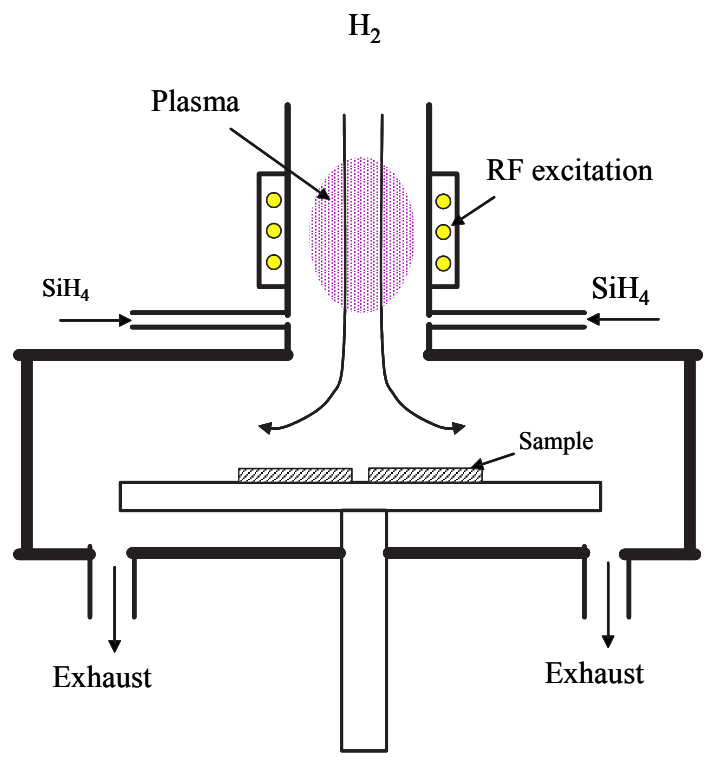

FIG. 1: Remote-PECVD reactor using radio frequency (RF) excitation.

\begin{tabular}{cr}
\hline \hline & \\
Silane $\left(\mathrm{SiH}_{4}\right)$ flow rate & $5[\mathrm{sccm}]$ \\
Hydrogen $\left(\mathrm{H}_{2}\right)$ flow rate & $150[\mathrm{sccm}]$ \\
Substrate temperatures & $50-400\left[{ }^{\circ} \mathrm{C}\right]$ \\
Working pressure & $0.4[\mathrm{Torr}]$ \\
R.F. power & $100[\mathrm{~W}]$ \\
Substrates & $\mathrm{Fz}(100), \mathrm{mc}-\mathrm{Si}$ \\
\hline
\end{tabular}

TABLE I: Deposition conditions for hydrogenated amorphous silicon (a-Si:H) films.

from $\mathrm{Si}-\mathrm{H}_{n}$ vibration-mode IR absorption [11]. The transmittance and reflectance spectra were measured with an integrating sphere photometer for the calculation of the absorption coefficient, and the optical band gap was obtained using a typical Tauc's plot [12].

Carrier lifetime measurements were performed using the quasi-steady state photo conductance (QSS-PC) technique [13]. The maximum values of the carrier lifetimes were obtained at a fixed injection level of $\Delta n=$ $1 \times 10^{15} \mathrm{~cm}^{-3}$. The as-grown wafer surface was chemically passivated with a $3 \%$ iodine/ethanol solution to derive a bulk lifetime. The effective carrier lifetime of the wafer in symmetric a-Si:H/mc-Si/a-Si:H after the deposition of the a-Si:H film at varied deposition temperatures was measured.

\section{RESULTS AND DISCUSSIONS}

\section{A. Effect of the a-Si:H film deposition temperature}

First, the thicknesses of the deposited a-Si:H films at various temperatures were measured and their deposition rates were calculated. Figure 2 shows the variations in the deposition rate as a function of the substrate temper-

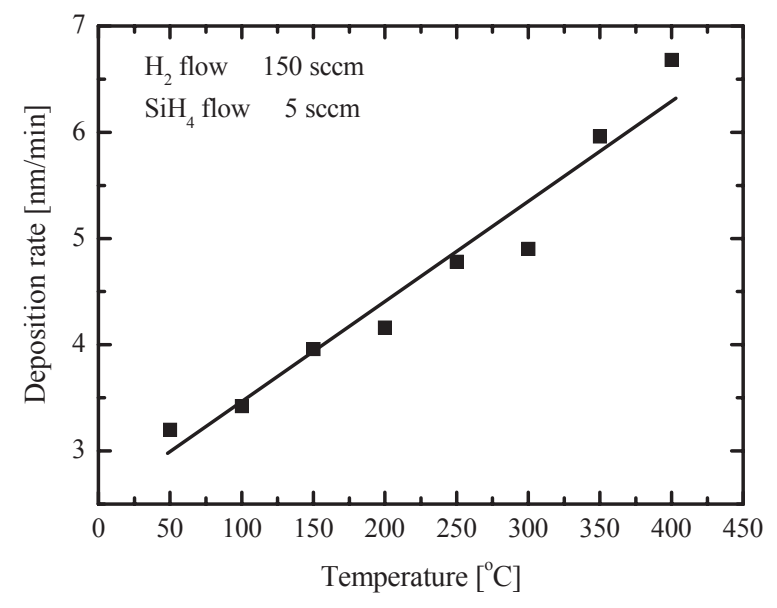

FIG. 2: Variation of deposition rate as a function of substrate temperature.

ature. The deposition rate of the a-Si:H films increased with increases in the substrate temperature from 3.2 to $6.7 \mathrm{~nm} / \mathrm{min}$.

To investigate the bonding structures of the asdeposited a-Si:H films, the films were deposited on an $\mathrm{Fz}$ (100) c-Si substrate at different temperatures that ranged from 50 to $400^{\circ} \mathrm{C}$ for $5 \mathrm{~min}$. The FTIR absorption spectra were displayed by coinciding the baselines of the transmission spectra and then converting the spectra to absorption using the Beer-Lambert law, $T=T_{0} e^{-\alpha(\omega) d}$, in which $d$ is the film thickness, $T$ and $T_{0}$ are the transmittance of the film substrate and the substrate, respectively, and $\alpha(\omega)$ is the absorption coefficient at frequency $\omega$. Figure 3(a) displays the FTIR absorption spectra in the wave numbers that ranged from 1,900 to $2,200 \mathrm{~cm}^{-1}$ with variations in the substrate temperature. In this figure, two peaks of the $\mathrm{Si}-\mathrm{H}$ stretching vibrations at $2,000 \mathrm{~cm}^{-1}$ and the $\mathrm{Si}-\mathrm{H}_{2}$ stretching vibrations at $2,090 \mathrm{~cm}^{-1}$ were observed. The bond changes occurred with increasing deposition temperature $\left(T_{\text {dep }}\right)$. The Si-H stretching mode was formed mainly at high temperatures above $200^{\circ} \mathrm{C}$, and the $\mathrm{Si}-\mathrm{H}_{2}$ stretching mode of the wave-number $2,090 \mathrm{~cm}^{-1}$ peaks, which means defects in the film, were formed mainly at low temperatures below $150^{\circ} \mathrm{C}$. At higher temperatures, the absorption peak shifted to lower wave numbers at around 2,000-2,090 $\mathrm{cm}^{-1}$. This confirms the aforementioned results: that the $\mathrm{H}$ was bonded in different configurations, which, in turn, were related to the deposition parameters; that the $T_{\text {dep }}<150^{\circ} \mathrm{C}$ effusion was associated with the $\mathrm{H}$ bonded in the $\mathrm{Si}-\mathrm{H}_{2}$ configuration; and that the $\mathrm{H}$ effusion at $T_{\mathrm{dep}}>200^{\circ} \mathrm{C}$ was related to the $\mathrm{H}$ bonded in the $\mathrm{Si}-\mathrm{H}$ configuration. Kessels et al. reported a similar behavior [14]. They found that the absorption peak shifted to lower wavenumbers around 2,000 from 2,090 $\mathrm{cm}^{-1}$. Furthermore, the 2,000 $\mathrm{cm}^{-1}$ FTIR absorption spectra decreased with an increase in the substrate temperature. $\mathrm{A} \mathrm{SiH}_{4}$ molecule, when decomposed at a high temperature, produces one $\mathrm{Si}$ and four $\mathrm{H}$ atoms. These are the primary generated radicals available for the film growth. The increase in the substrate temperature is expected to increase the proportion of atomic Si and $\mathrm{H}$ in the gas phase. Thus, only mono-hydrogen ( $\mathrm{Si}-\mathrm{H})$ 

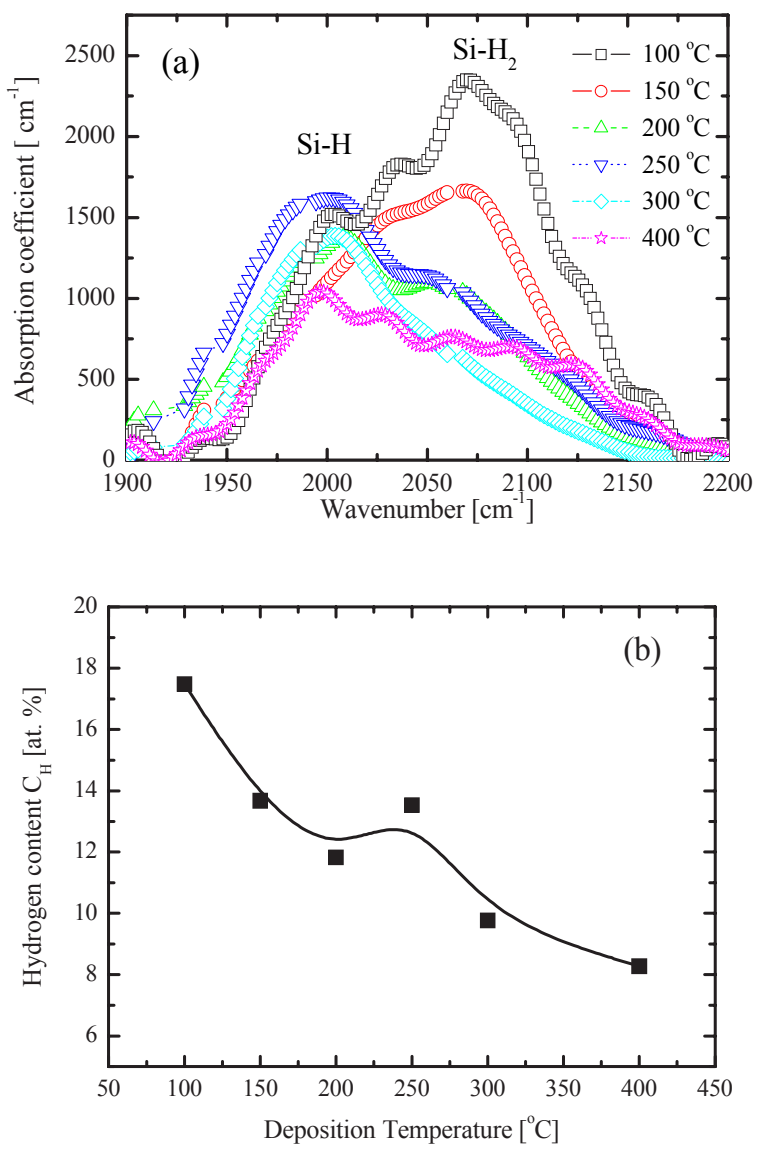

FIG. 3: (a) FTIR absorption spectra in the wavenumbers range of $1900-2200 \mathrm{~cm}^{-1}$ with variation of substrate temperature. (b) Hydrogen contents $\left(C_{\mathrm{H}}\right)$ in a-Si:H films determined from Fig. 3(a).

bonding configuration can be expected at a high temperature. The $\mathrm{Si}-\mathrm{H}$ and $\mathrm{Si}-\mathrm{H}_{2}$ bonds were found to have been very sensitive to the deposition temperature. These differences arise from the different concentrations of $\mathrm{SiH}$, $\mathrm{SiH}_{2}$, and $\mathrm{SiH}_{3}$ bonds in the deposited a-Si:H film [15]. It can be assumed that high-quality films that have a low defect density were obtained at high temperatures of above $200^{\circ} \mathrm{C}$. The hydrogen content $\left(C_{\mathrm{H}}\right)$ was estimated from the above-FTIR absorption spectra (see Fig. 3(a)). The density of the $\mathrm{Si}-\mathrm{H}_{n}$ bond $N_{\mathrm{H}}$ can be calculated using the relationship $N_{\mathrm{H}}=A \int[\alpha(\omega) / \omega] d \omega$ integrated on the $2,000-2,100 \mathrm{~cm}^{-1}$ band, in which $A$ is a constant $\left(=1.4 \times 10^{20} \mathrm{~cm}^{-2}\right)[16,17]$ and $\alpha(\omega)$ is the absorption coefficient at frequency $\omega . C_{\mathrm{H}}$ was calculated from the following ratio: $C_{\mathrm{H}}=\left[N_{\mathrm{H}} /\left(N_{\mathrm{H}}+N_{\mathrm{Si}}\right)\right] \times 100$ [at. \%], in which $N_{\mathrm{Si}}$ is the density of the silicon atoms $\left(N_{\mathrm{Si}}=\right.$ $5 \times 10^{22} \mathrm{~cm}^{-3)}$. Figure $3(\mathrm{~b})$ shows the variations in the hydrogen content $\left(C_{\mathrm{H}}\right)$ as a function of the substrate temperature. As seen from the figure, the $C_{\mathrm{H}}$ in the film decreased from 17.5 to 8.3 at. $\%$ when the substrate temperature increased from 100 to $400^{\circ} \mathrm{C}$. This shows that the $\mathrm{H}$ concentration can vary the substrate temperature.

To estimate the optical properties, the a-Si:H films were deposited on a Corning \#1737 substrate at various temperatures. The reflectance and transmittance (R\&T) measurements were performed in wavelengths that ranged

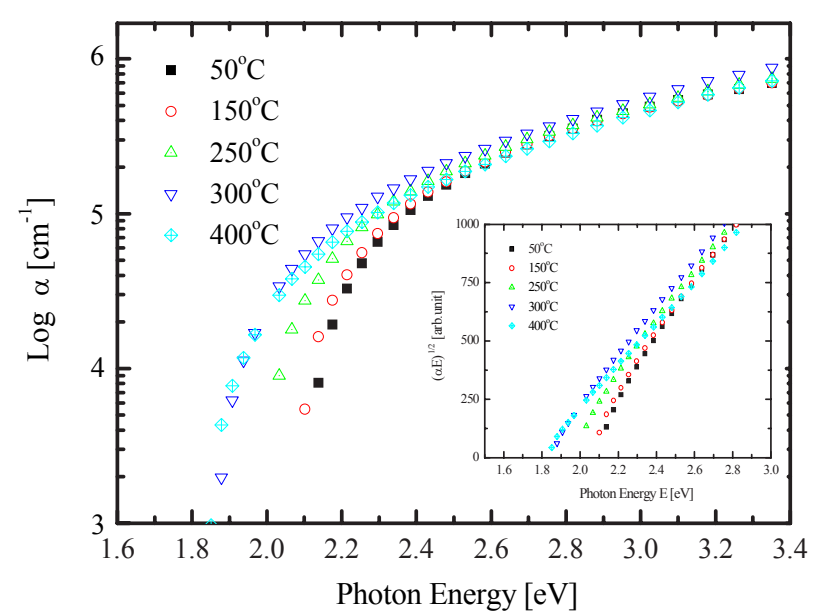

FIG. 4: Absorption coefficient $(\alpha)$ and optical band gap of asdeposited a-Si:H films at different temperatures as a function of the incident photon energy.

from 300 to $1,200 \mathrm{~nm}$. The absorption coefficient $\alpha$ was calculated from the measured R\&T of the a-Si:H films deposited at different temperatures according to the following equation: $\alpha=[1 / d] \ln [(1-R) / T]$, in which $d, R$ and $T$ are the thickness, the reflectance, and the transmittance of the a-Si:H films, respectively. Figure 4 shows the variations in the absorption coefficient of the a-Si:H films deposited at different temperatures as a function of the incident photon energy. As can be seen in Fig. 4, the impact of the deposition temperature on the absorption coefficient was very small at higher-photon-energy regions. At lower-photon-energy regions, however, higher absorption coefficients were found with increasing deposition temperature.

The optical band-gap $\left(E_{\mathrm{opt}}\right)$ of the deposited a-Si:H films at different temperatures can be obtained from the intercept of the slope of the square root of the photon energy and the absorption coefficient product $\sqrt{\alpha \cdot h \nu}$ vs. the photon energy $h \nu$ on the $\mathrm{x}$ axis of Tauc's plot at $\sqrt{\alpha \cdot h \nu}=0$. The optical band-gaps were calculated from the absorption coefficient, as shown in the inset in Fig. 4. The $E_{\text {opt }}$ in the films decreased almost linearly from 2.05 to $1.76 \mathrm{eV}$ with increases in the deposition temperature. This was due to the reduction in the $C_{\mathrm{H}}$ and the improvement of the localized states with increases in the substrate temperature (see Fig. 3(b)). It was also noted that the optical band gap decreased with increases in the substrate temperature for the film that was deposited without the $\mathrm{Si}-\mathrm{H}_{2}$ stretching mode, which means defects in the films. Because, the $\mathrm{Si}-\mathrm{H}_{2}$ bond can be easily formed dangling bonds, which affect the surface passivation inferiorly in films, due to the weak bonding structures $[15,18]$.

\section{B. Effect of the annealing treatment on multicrystalline Si wafer}

To measure the effective carrier lifetime, p-type $\mathrm{Fz}$ (100) and p-type mc-Si wafers with thicknesses of about $230 \mu \mathrm{m}$ were used. These crystalline Si wafers were cut into $2 \mathrm{~cm} \times 2 \mathrm{~cm}$ substrates, etched in an $\mathrm{HF}: 6 \mathrm{HNO}_{3}$ 

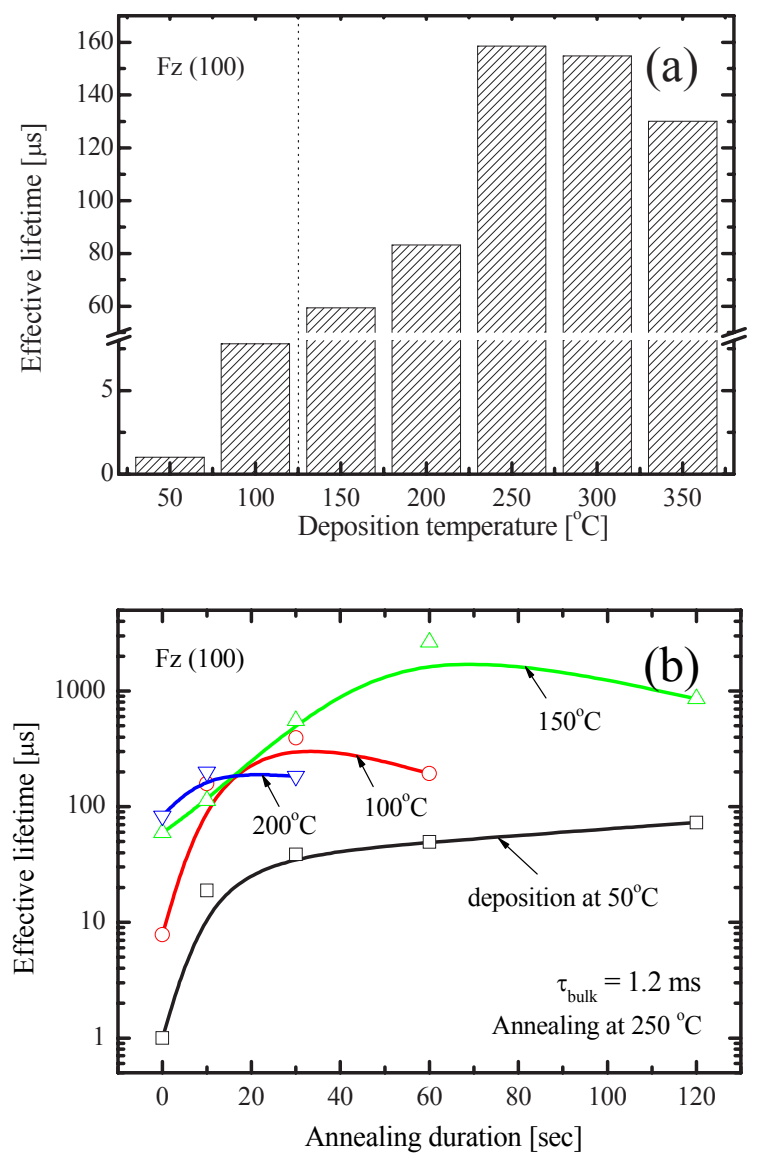

FIG. 5: (a) Change of the effective carrier lifetime $\left(\tau_{\text {eff }}\right)$ in Fz $\mathrm{Si}$ substrates coated with a-Si:H layers at various deposition temperatures. (b) Effect of the eff of silicon wafers passivated with a-Si films deposited at 50, 100, 150 and $200^{\circ} \mathrm{C}$ after annealing treatment at $250^{\circ} \mathrm{C}$.

solution to remove saw damage, dipped in a $5 \%$ diluted HF solution to remove the native oxide layer, and rinsed in pure water. The substrates after the $5 \%$ diluted HF treatment were immediately placed in the experimental chamber, which was then pumped down. Hydrogen radical treatment was carried out on the wafers for $2 \mathrm{~min}$ before the deposition of the a-Si:H film at various temperatures. The a-Si:H films were deposited on the wafers at various temperatures.

Prior to the investigation of the mc-Si, an optimal a$\mathrm{Si}: \mathrm{H}$ film deposition condition on the $\mathrm{Fz}$ c-Si wafers was found to avoid the effect of the grain boundary in the mcSi. Figure 5(a) shows the effective carrier lifetime $\left(\tau_{\text {eff }}\right)$ of the a-Si:H films deposited on the $\mathrm{Fz}$ c-Si wafers at various substrate temperatures. It was found that the effective carrier lifetime depended strongly on the deposition temperature. The highest effective carrier lifetimes were found after the deposition of the a-Si:H films at $250^{\circ} \mathrm{C}$. Several researchers have reported similar results with respect to the optimal deposition temperature $[4,19]$. To further improve the lifetimes, all the wafers of the a-Si:H films deposited at different temperatures were thermally annealed at $250^{\circ} \mathrm{C}$. The results are shown in Fig. 5(b). As the figure shows, the improvement in the highest carrier lifetime was obtained in the a-Si:H film deposited at

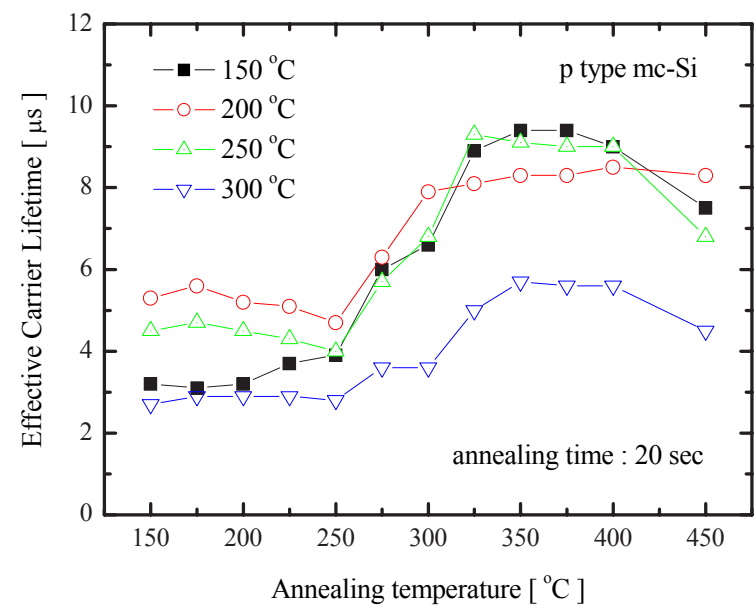

FIG. 6: Dependence of effective carrier lifetime $\left(\tau_{\text {eff }}\right)$ on annealing temperature in mc-Si wafers passivated with bifacial a-Si:H films formed at various temperatures. The effective carrier lifetimes were measured by the QSSPC technique at a fixed injection level of $\Delta n=1 \times 10^{15} \mathrm{~cm}^{-3}$.

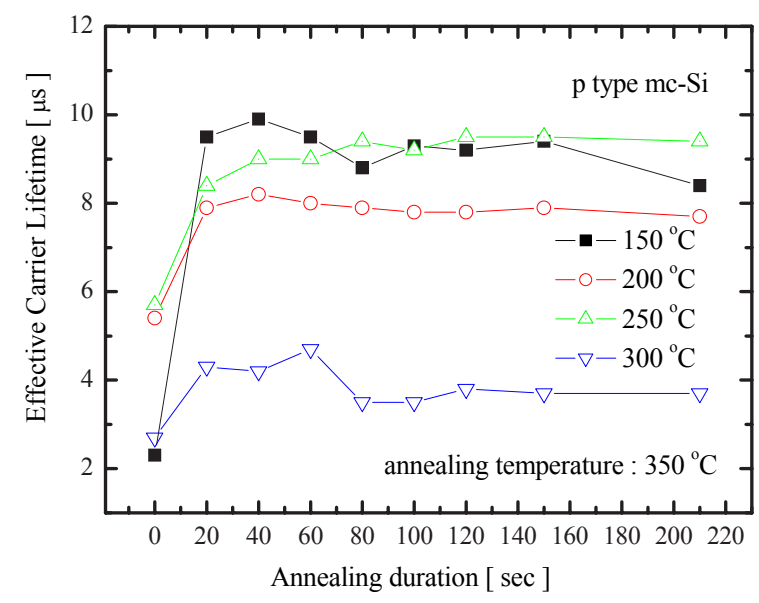

FIG. 7: Dependence of effective carrier lifetime $\left(\tau_{\text {eff }}\right)$ on annealing treatment duration in mc-Si wafers passivated with bifacial a-Si:H films. The annealing temperature was set to $350^{\circ} \mathrm{C}$.

$150^{\circ} \mathrm{C}$ after annealing treatment for $60 \mathrm{sec}$. The $\tau_{\text {eff }}$ improved drastically by about 50 times compared with that of the as-deposited a-Si:H film. These results show that annealing treatment is essential in improving the effective carrier lifetime.

Based on the aforementioned results, the a-Si:H films that were bifacially deposited on about $2 \Omega \mathrm{cm} \mathrm{mc}-\mathrm{Si}$ wafers at various deposition temperatures were investigated. The effective carrier lifetimes of the mc-Si wafers after the deposition of the a-Si:H films at 150 to $300^{\circ} \mathrm{C}$ were estimated at a fixed injection level of $\Delta n=10^{15} \mathrm{~cm}^{-3}$. After the deposition of the a-Si:H films on the mc-Si wafers, the best effective carrier lifetime was found to have been about $5.7 \mu \mathrm{s}$ at $250^{\circ} \mathrm{C}$, which was slightly high compared to the lifetime of the same wafers passivated chemically with a $3 \%$ iodine ethanol solution of about $5.2 \mu \mathrm{s}$. As seen in Fig. 3(a), the amount of the 

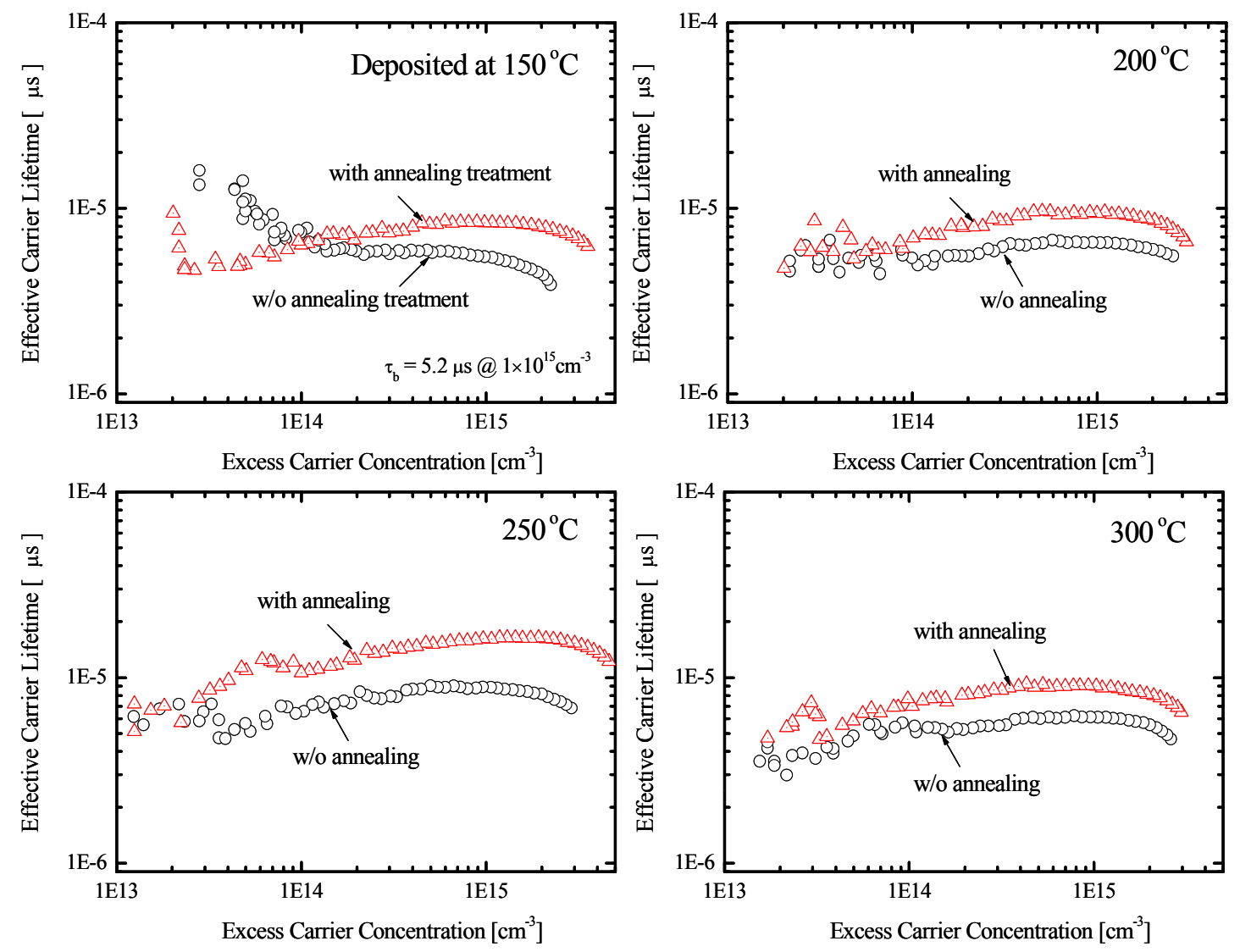

FIG. 8: Effective carrier lifetimes versus the excess carrier concentration of the mc-Si wafers with and without the annealing treatment.

$\mathrm{Si}-\mathrm{H}$ bond is proportional to the effective carrier lifetimes at various temperatures. It indicates that the Si-H bonds, which mean a good film quality, were strongly related to the effective carrier lifetimes. Because, the Si-H stretching mode of wavenumber $2,000 \mathrm{~cm}^{-1}$ peak is very stable in films and it well passivate the dangling bonds on c-Si surface $[15,18]$.

For further effective carrier lifetime improvement, the annealing treatment was investigated in the air using a hot plate. Figure 6 shows the annealing treatment temperature dependence of the effective carrier lifetimes of the a-Si:H films deposited on mc-Si wafers at various temperatures. The annealing duration was kept constant at $20 \mathrm{sec}$, and the annealing treatment temperature increased at $25^{\circ} \mathrm{C}$ intervals. As Fig. 6 shows, the effective carrier lifetimes increased with increases in the annealing temperature until they reached their maximum temperature at $350-400^{\circ} \mathrm{C}$, after which they decreased again with increases in the annealing treatment temperature. The optimal annealing treatment temperature was found to have been around $375^{\circ} \mathrm{C}$. The best effective carrier lifetime after deposition was achieved in the films deposited at $250^{\circ} \mathrm{C}$ before annealing for the as-deposited films. The improvement in the carrier lifetimes of the a-Si:H films deposited at 150 and $250^{\circ} \mathrm{C}$ after annealing treatment was higher than those of the a-Si:H films deposited at $200^{\circ} \mathrm{C}$. This may have been due to the effect of the hydrogen content, as Fig. 3(b) shows. The same results were seen in the Fz wafers, as Fig. 5(b) shows. After the wafers were annealed at above $250^{\circ} \mathrm{C}$, the increase in the effective carrier lifetimes started. The effect of the annealing treatment on the mc-Si wafers was strong with respect to the wafers passivated with a-Si:H that was deposited at temperatures below $250^{\circ} \mathrm{C}$. The effective carrier lifetimes improved with increases in the deposition temperature. At a higher deposition temperature of around $300^{\circ} \mathrm{C}$, however, the impact of the annealing treatment was not strong, as Fig. 6 shows. Next, the effect of the annealing treatment duration was investigated. Chosen as the optimal annealing treatment temperature was $350^{\circ} \mathrm{C}$, from the aforementioned results. Figure 7 shows the dependence of the effective carrier lifetime on the annealing duration of the a-Si:H films at the annealing temperature of $350^{\circ} \mathrm{C}$. The effective carrier lifetimes were measured at $20 \mathrm{sec}$ annealing intervals. The effective carrier lifetimes rapidly increased after $20 \mathrm{sec}$. The mc-Si wafers passivated with a-Si:H films deposited temperatures below $250^{\circ} \mathrm{C}$, the eff improved drastically to about 2-5 times its as-deposited value, and the effective carrier lifetimes were immediately saturated. The $\tau_{\text {eff }}$ of the a-Si:H films deposited above $300^{\circ} \mathrm{C}$ did not improve, though. This could show that the improvement in the carrier lifetimes was due to the effect of the hydrogen content, as Fig. 3(b) shows.

Finally, the a-Si:H films deposited on the mc-Si wafer at various temperatures were etched off in an $\mathrm{HF}: 6 \mathrm{HNO}_{3}$ solution, and the wafers were chemically passivated (CP) with a $3 \%$ iodine ethanol solution to estimate the bulk carrier lifetimes with and without the annealing treat- 
ment. Figure 8 shows the apparent effective carrier lifetimes versus the excess carrier concentration of the wafers with and without the annealing treatment. After the deposition of the a-Si:H films, the effective carrier lifetimes all increased compared with the lifetimes of the chemically passivated same wafers. Moreover, the effective carrier lifetimes further increased after the annealing treatment. This could have been due to the reduction of the silicon dangling bonds in the mc-Si region by thermally activated hydrogen atoms in the a-Si:H films as a bulk passivation effect. In particular, the effective carrier lifetime of the a-Si:H film deposited at $250^{\circ} \mathrm{C}$ after the annealing treatment drastically increased by about 3 times compared with the bulk carrier lifetime. The improvement in the effective carrier lifetime could have been due to the high-quality film, though, which included a few structural defects and high hydrogen content (see Fig. 3). The effective carrier lifetimes depended strongly on the a$\mathrm{Si}: \mathrm{H}$ film deposition temperature and the annealing treatment. These results indicate that a combination of a-Si:H film deposition and annealing treatment can improve the bulk carrier lifetimes due to the strong bulk passivation effect. Therefore, forming an a-Si:H intrinsic layer at a low temperature is expected to be advantageous for heterojunction solar cells.

\section{CONCLUSION}

To investigate the effect of a-Si:H intrinsic thin layers deposited on p-type mc-Si wafers for heterojunction so- lar cells, a-Si:H thin films were prepared using the radiofrequency remote PECVD method, and the impact of the deposition temperature on the a-Si:H films' properties and the passivation effect were evaluated. The structural properties of the a-Si:H films formed at various deposition temperatures changed with increasing deposition temperature. After the annealing treatment, the wafers passivated with a-Si films showed temperatures of below $250^{\circ} \mathrm{C}$, and the effective carrier lifetime drastically improved to about 2-5 times its as-deposited value and over the chemical passivation lifetime. Furthermore, the effective carrier lifetimes of the a-Si:H films after the annealing treatment improved. The effective carrier lifetimes increased with increases in the deposition temperature until they reached the maximum at $250^{\circ} \mathrm{C}$. The effective carrier lifetimes drastically improved after the annealing treatment. The optimal annealing temperature for the a-Si:H films was around $350^{\circ} \mathrm{C}$. The annealing treatment was effective with a short annealing duration of $20 \mathrm{sec}$. This experiment showed that a combination of a-Si:H film deposition and annealing treatment provides excellent bulk passivation.

\section{Acknowledgments}

This work was supported by Incorporated Administrative Agency New Energy and Industrial Technology Development Organization (NEDO) under Ministry of Economy, Trade and Industry (METI).
[1] T. Sawada, N. Terada, S. Tsuge, T. Baba, T. Takahama, K. Wakisaka, S. Tsuda, and S. Nakano, Proc. of the 1st World Conference on Photovoltaic Energy Conversion, 1219 (1994).

[2] M. Tanaka, M. Taguchi, T. Mastuyama, T. Sawada, S. Tsuda, S. Nakano, H. Hanafusa, and Y. Kuwano, Jpn. J. Appl. Phys. 31, 3518 (1992).

[3] M. Taguchi, K. Kawamoto, S. Tsuge, T. Baba, H. Sakata, M. Morizane, K. Uchihashi, N. Nakamura, S. Kiyama, and O. Oota, Prog. Photovolt.: Res. Appl. 8, 503 (2000).

[4] S. Dauwe, J. Schmidt, and R. Hezel, Proc. of the 29th IEEE Photonoltaic Specialist Conference, 1246 (2002).

[5] M. Taguchi, A.Terakawa, E. Maruyama, and M. Tanaka, Prog. Photovolt.: Res. Appl. 13, 481 (2005).

[6] T. H. Wang, E. Iwaniczko, M. R. Page, Qi Wang, Y. Xu, Y. Yan, D. Levi, L. Royval, R. Bauer, and H. M. Branz, Proc. of the 4th World Conference on Photovoltaic Energy Conversion, 1439 (2006).

[7] A. G. Aberle and R. Hezel, Prog. Photovolt.: Res. Appl. 5, 29 (1997).

[8] C. H. Jeong, S. J. Boo, M. S. Jeon, and K. Kamisako, J. Nanosci. Nanotech. 7, 4169 (2007).

[9] H. Fujiwara, J. Koh, P. I. Rovira, and R. W. Collins, Phys.
Rev. B 61, 10832 (2000).

[10] H. Fujiwara and M. Kondo, Proc. of the 4th World Conference on Photovoltaic Energy Conversion, 1443 (2006).

[11] E. C. Freeman and W. Paul, Phys. Rev. B 18, 4288 (1978).

[12] J. Tauc, in: F. Abeles (Ed.), Optical Properties of Solids (North-Holland, Amsterdam, 1972), pp. 277-307.

[13] R. A. Sinton and A. Cuevas, Appl. Phys. Lett. 69, 2510 (1996)

[14] W. M. M. Kessels, P. J. van den Oever, J. J. H. Gielis, B. Hoex, and M. C. M. van de Sanden, Proc. of the 4th World Conference on Photovoltaic Energy Conversion, 1616 (2006).

[15] W. Theis, Surf. Sci. Rep. 29, 91 (1997).

[16] A. A. Langford, M. L. Fleet, P. Nelson, W. A. Landford, and N. Maley, Phys. Rev. B 45, 13367 (1992).

[17] D. K. Basa and F. W. Smith, Thin Solid Films 192, 121 (1990).

[18] H. Kakinuma, M. Mohri, M. Sakamoto and T. Tsuruoka, J. Appl. Phys. 70, 7374 (1991)

[19] M. Schaper, J. Schmidt, H. Plagwitz, and R. Brendel, Prog. Photovolt.: Res. Appl. 13, 381 (2005). 